\title{
Analysis on Discrimination Governance: Individual Dilemma and Relief Mechanism
}

\author{
Hao $\mathrm{Li}^{1}{ }^{1, *}$ \\ ${ }^{1}$ Sun Yat-sen University, Guangzhou, China,510006 \\ *Corresponding author. Email: steptenlee@163.com
}

\begin{abstract}
Against the backdrop of deployment of artificial intelligence and automation technology, the main form of discrimination are changing in human society. Compared with the traditional statistical discrimination, personality discrimination regarding individuals' features contributes to not only a deeper crisis to human dignity and right of equality, but also more barriers for citizens to safeguard their own right. Legal intervention is required while at least three defects are found at present: asymmetrical discourse in legislation, opaque data processing regime in substantial law and immature dispute solution in procedural law. This paper tries to explore to deal with the issues above, what kind of normative framework should we build up? And, for details, what improvements should be made to the current law and policy? From the perspective of comprehensiveness and effectiveness, there is a necessity of adoption of more representative legislation taking individuals into consideration, transparent information system including the right to access as well as right to delete, and diversity dispute solution institution relying on industry autonomy, administrative supervision and litigation. Only with that can we effectively tackle the challenge caused by arising phenomenon and improve digital human right of great concern.
\end{abstract}

Keywords: artificial intelligence, personality discrimination, discourse, data processing regime, dispute solution.

\section{INTRODUCTION}

With the advancement of the third scientific revolution, the popularization of information network and automation technology has become a fact and trend without doubt. Apart from plenty of convenience and productivity it brings, adverse effect related to new technique should also not to be ignored. Grabbing massive data and AI analysis makes personal electronic archives possible [1], thus leading to the historical process from statistical discrimination to personality discrimination [2]. Judging a person in accordance with external characteristics of the groups he belongs to, such as the stereotype of race, gender, ethnic, class, nation and so on, is the so called statistical discrimination. As a result of insufficient information, it might be view as the most cost-effective approach of assessment (despite not necessarily [3]), so that it become prevalent in the past. However the arrival of dig data era have changed the situation, not shortage but excessive information supply steer the discrimination pattern in a individual direction. Personality discrimination, the counterpart concept of statistical discrimination, focus on individual features like personal consumption preference, social credit, crime record, appearance, health condition and so on. For example, website push distinctive advertises according to your search interest, app impose higher price on the customer with stronger dependence on itself, and polices check the passengers identified likely to be suspicious more frequently on street, etc. Insofar, there is a period of transition interwoven by two type of discrimination, but the latter one would come into mainstream in the years ahead [2]. Obviously, by evaluating precisely and treat people differently, personality discrimination perform task that allocate human resource and reduce security risk, which constitute the basic requirement of modern governance.

Benefits notwithstanding, the challenges posed by personality discrimination to the existing legal order are shown in the following two points: firstly, the violation of the traditional right to personality and the right to equality. Those elemental value are of significance in human society. Hilus believes that it is improper and cruel to disclose the defects of others [4], then Marcelo allude uniformity in affirming equality and identifying law 
subject [5]. Secondly, the complication for individuals in safeguarding the legal rights. Victor believes that the counter effect of the right to information privacy is not clear [6], and Wang Liming puts forward that moral human rights are difficult to obtain legal relief [7].

With above problems to be noticed, here comes a attempt for the legal scholars and legislators to mitigate the negative influence. Hence, this paper strive to explore what results in this new technique-related bias pattern from perspectives of legislation,substantial law and procedure. In other words, a outcome-based and data subject-oriented, sort of utilitarianism angle and research method. And with such concern, after observing relevant theories and legal practices around the world, the author would like to put forward some suggestions tackling the issues and protecting the digital privacy and right to equality.

\section{LEGAL COURSE OF THE DEEPER DISCRIMINATION}

\subsection{One-way discourse and individual silence}

Since human beings implemented democratic politics and representative system, the legislature has become a arena for various interest groups. The strong side monopolizes the discourse and affects the legislative process to ensure its own rights and interests, while the weak side is not. The Internet industry has led to a new class division,some therefore gain more power than the rest [6]. Pursuing different purposes (Internet enterprises for profit and government for society order), data controller tend to ignore the protection of individuals. As what we can see, Robin Li told the media that Chinese people are less sensitive to privacy issues [8]. This reflects the Internet companies overlook the rights and interests of users and the lack of sense of social responsibility.

Even though the information industry giant and public sector has a great impact on enactment of law, however, in the circumstance of discrimination,the antagonistic solidarity of groups can offset inequality. What can be regarded as a model is a series of affirmative actions in the United States after World War II. The discriminated individuals gathered under the flag of race, gender, sex orientation and others respectively, fought against the unfairness and finally changed the code. The abolition of racial segregation policy in southern states and the promulgation of civil rights law are the symbol of victory of that movement. While things got different in the scene of discrimination, individual citizens have to face highly targeted prejudices alone most of the time. It is because the new bias form have something to do with one's unique or embarrassed experience, which he does not want to espoused to the public just as others does not want him to know, that sufferers always remain isolated and scattered (the extent to which they can form a group is still questionable). It may be common for ethnic minorities to demonstrate in front of the legislature, but it is difficult to image victims of rape who have been discriminated against or people with a record of theft to do so. Besides, due to the rapid shift of technology and social face, newly occurred personality discrimination is hard to find for both person aggrieved and legislation department. In Changsha, passengers whose electronic health code without record of vaccination of COVID-19 are not allowed to enter the subway station unless their name, contact information, ID number, home address, unvaccinated reason, etc. are registered [9], while most citizens do not take it as prejudice.

\section{2. "Black box" of data processing system}

Cross-platform usage of personal information and a automatic processing system, give rise to the abuse of user profiling. Private corporations adopt it to design and operate products, while the public sector uses it in areas such as public security. With the help of powerful AI, date controller even understand the individuals more that themself. What a horrible picture that there is always someone (the big brother) keep his eyes on you and everyone have to act as they are under surveillance even though not under surveillance--in fact, this is the panoption prison proposed by Bentham and reiterated by Foucault, an efficient discipline tool at the expense of the freedom and privacy of the regulated. The asymmetric relationship between enterprises that design the and public is common in the information society. Unlike bias toward groups resulted from the wrong database and biased samples [10], or underrepresentation and exclusion and oversurveillance in data selection and design artificial intelligence [11], what make personality discrimination happen is the failure for the data subject to control their personal information comprising of privacy.So important a role AI play in everyday life that citizens should pay attention to the logic it run--the algorithm. Nevertheless, beside the reason non professionals cannot understand the it, the designers prefer to keep algorithm secret to maintain a dominant position.

The legal action took by Ren Jiayu against Baidu is a sample that individual struggle to challenge algorithm hegemony. Since the beginning of February 2015, Ren Jiayu has successively found the infringing contents and links of "Taoshi education Ren Jiayu" and "Wuxi Taoshi education Ren Jiayu" on Baidu's website, although he has not worked for that company and never upload anything related to the internet. Different from the self-making data footprint of another case "ZhuYe v. Baidu", those marks belongs to self-making trail [12], which means, the outcome of AI. Because of the bad reputation of Taoshi education enterprise, Ren's career was greatly affected. Thus he sued the Baidu for the deletion of the relevant information online, while not supported by the court. The 
judge held that the search engine service provider only objectively displayed the search behavior of Internet users for the reference of network users, and did not make any artificial adjustment and intervention in the service process, so there was no infringement [13]. Ramification of this case indicates a long distant to the data processing system in which data subjects would get involved.

\subsection{Immature dispute solution mechanism}

Almost all industrialized countries solve the problem of information privacy with law [14], however, the actual effect remains to be investigated. As mentioned above, the secrecy of operation makes it difficult for people to find out who has been discriminated against and, as well as by whom. Personality discrimination refers to data collectors (different platforms), data processors, data savers and data traders, and sometimes regulators. When it comes to third party outsourcing services, situation get more complicated. Facing it, individuals without enough knowledge of law and IT always fail to identify the defendant. In addition, if users or consumers are slanted to exercise their right in judicial mode, they have to take the cost of time and money into consideration. Not only high spending, but also less revenue gain from the litigation contributes to the fact that few people go to the court to claim their right [6].

What should be specially noticed is the fatal weakness in judicial practice, that is, the contradiction between the openness of the trial and the privacy of information related to personality discrimination. Rather than strengthening the subject's control over information, judicial intervention completely deprives it of its control over information and destroys the possibility of information autonomy, resulting in more serious consequences. Similar phenomenon is called "streisand effect", which is famous for the attempt by the actress named Streisand to delete pictures about her house but make it more concerned. After going through "Google V. Mario Costeja González", known as the first case of the right to be forgotten, litigant's disgraceful experience has changed from little known to the object of the mainstream media [15]. It can be seen from the above that there are many shortcomings in solving the problem of personality discrimination regarding information technology through judicial path, thus it is better to call for a more flexible regime consist of plural methods.

\section{NORM AND REGULATION OF ANTI- DISCRIMINATION}

\subsection{Legislative process of individual participation}

The past history of mankind has proved that legislation without representativeness will eventually become a tool for rulers and even breed a terrible picture of tyranny. However, representativeness does not only mean that the minority obeys the majority (the danger of mob dictatorship), but also means humanistic care for each individual. Fairness and justice have no meaning unless they can be realized in individuals. This is particularly important when today's data aggregation and artificial intelligence increase the class gap: the data controller obtains an unprecedented discourse, and the data subject is constantly divided into scattered individuals. Disintegration of groups and the trend of disappearance of discrimination remind legislators of the importance of individual participation. Only living individuals, as users and citizens, can accurately express the personality discrimination they face and put forward effective institutional demands. For instance, public criticism of price discrimination prompted the introduction of the data regulations of Shenzhen Special Economic Zone and increased the punishment for this behavior (up to 5000 RMB) [16]. Besides restricting interest groups and preventing them from manipulating legislation by means of public opinion and lobbying, citizens also should be entitled to more discourse. Among stakeholders, there should be a more equitable policy and regulation [17]. On the one hand, people's representatives should carefully listen to the voice of every citizen; on the other hand, legislation department ought to establish a citizen anonymous petition and protest regime.

What's more, the concept of personality discrimination should be recognized by jurisprudence and legislative practice. This is not a issue only related to public law or private law, or limited to the field of law. In the era of big data, mankind will face this dilemma together at the level of social governance. Therefore, the idea of solving problems must be comprehensive and cooperative. Face recognition, search engine, advertising push, robot, user platform, electronic archives, etc. from these trivial appearances, we should abstract something of unity. After grasping its essence, we try to explore the internal normative: as technical rationality, it is also legal rationality. The active exchanges between the academic and legislative circles globally will help to achieve this goal.

\subsection{Right to access and delete}

The right of information self-determination originated in Germany, which aims to ensure the individual's control over the collection, processing, utilization and transfer of relevant information, so as to avoid illegal infringement. Although countries all over the world hold different attitudes towards it, most of them agree with the ethical value behind it. Losing dominance of personal information is main reason of discrimination. The theory of personal information self-determination provides a basic framework for us to explore how to 
realize the regulation of data processing system from the dimension of substantive law.

In order to break the algorithm black box and realize the transparency and accountability of the whole industrial chain, at least two rights should be confirmed: right to access and right to delete. As a matter of fact, some countries and regions have made useful attempts. For example, the EU's general data protection regulations, which came into force in 2018, has become an upper standard that the legislatures of EU countries must try to follow. Article 17 of the act is named "right to delete (right to be forgotten)", which systematically illustrated the right to be forgotten in legislation for the first time after the case "Google V. Mario Costeja González". After 16 years of discussion and improvement, personal information protection law of the Chinese mainland was passed in August this year. Inside it, Article 45 guarantees the right to access of the information subject, and Article 47 is related to the right to delete. These two rights participate in the construction of the subject of information rights. Despite a lot of countries seem to have enacted relatively perfect laws, the actual effect in eliminating personality discrimination and protecting other digital human rights is still waiting for further observation. At the same time, more details, including right object (especially the sensitive data concerning stigmatism [18]), right content and exemption clause, still need to be fed back by practice, so as to keep pace with the age. The guaranteed right to access and right to delete will change the excessive collection and analysis of data, which forms the current situation of one-way power. Therefore, the personality discrimination based on oneway power, although will not annihilated at present, at least weakened.

\subsection{Litigation and non-litigation approach}

If the victims of personality discrimination need help from the court, they have to face a complex litigation situation. As plaintiffs, they lack the ability to judge the defendant among multiple subjects related to data processing. In addition, high litigation costs, time and energy expenditure and disproportionate benefits also effectively deter litigation. Despite distributed, there is a huge amount of the victims, which mean a relationship with public interest. Hence, the public sector such as Police station and procuratorate and, if possible, some social organizations like consumer protection association should bear the litigation responsibility. For instance, Article 70 of personal data protection law in the Chinese Mainland provides for public interest litigation, then the Supreme People's Procuratorate issued the notice on implementing the personal information protection law and promoting the procuratorial work of public interest litigation for personal information protection, standardize the handling of relevant public interest litigation cases [19]. These institutions have sufficient resources to compete with strong data controllers to provide relief to individual citizens. Meanwhile, to prevent further personality discrimination, some confidentiality measures like restriction on Audit and media coverage is necessary.

In addition to litigation, more efficient and low-cost dispute resolution methods are industry autonomy and government supervision. Actually, this is also the way most disputes can be resolved. For example, the deletion request mechanism of Google, Baidu, ETC. and the handling of data complaints by the Privacy Commissioner of Hong Kong. The non-litigation settlement path can not only deal with disputes quickly, but also avoid the Streisand effect. Those should be strongly encouraged in dealing with algorithmic discrimination. And measures should take to attenuate the hardship of honest mistakes when responsibilities attached to intermediaries [20]. Nevertheless, on the other side of the efficiency advantage is the concern about fairness. Industry autonomy is likely to cause "black box of judgment" because of being their own judge. The government also has this concern when dealing with discrimination complaints related to itself. Therefore, while constantly improving the non-litigation path, we should still give play to the guidance and correction function of litigation. Let the judiciary be the last line of defense of justice and supervise enterprises and the government. Only when the litigation path and nonlitigation path cooperate with each other, give consideration to efficiency and fairness, and realize the effective regulation of artificial intelligence and algorithms, can it be possible to deal with the new challenge of personality discrimination, so as to protect human dignity and peace of life.

\section{CONCLUSION}

Information technology not only brings human wellbeing, but also reflects on the nature of norms and social order. The development of artificial intelligence and big data has realized the archival writing of individuals, resulting in a finer and deeper bias. Personality discrimination is not based on group characteristics, but related to individual experience. People are at the historical node of the transition from statistical discrimination to personality discrimination, and have to face a more serious right crisis: both the violation of traditional legal interests and the dilemma in the practice of safeguarding rights.

As a matter of facet, individual citizens face Leviathan of data capital and power alone. To get out of this jungle, we call for legal reform, because the existing normative framework is not sufficient to provide protection. This paper discusses three causes of personality discrimination from the current norms:oneway legislative discourse, algorithm black box and immature dispute handling system. Accordingly, we 
should try to balance the discourse in terms of legislation, establish a regime for individual participation, and introduce the concept of personality discrimination in legal theory and parliamentary discussion. Break the opaque and solidified state of data processing, entitle data subjects right to access and right to delete, so that ensure their control over relevant information. Finally, establish a diversified dispute resolution system including litigation and non-litigation paths to provide procedural guarantee for individuals. These measures are expected to deal with the problem of personality discrimination brought by information technology, so as to protect the digital personality right and the basic value of mankind. The author believes that with the further research, the relationship between technological development and discrimination as well as privacy will be examined from different perspective, and the legal values and normative framework in the post industrial era will be more perfect at that time.

\section{AUTHORS' CONTRIBUTIONS}

This paper is independently completed by Hao Li.

\section{ACKNOWLEDGMENTS}

The idea of this article mainly comes from the courses of Professor Katyal of University of California, Berkeley, during which I received her serious guidance. At the same time, the suggestions of my classmates and the support of my family also helped me a lot. Therefore, I would like to express my gratitude to them.

\section{REFERENCES}

[1] Lan Jiang. Profiling of Life, Algorithmic Governmentality and Precariat-Life Politics in Digital Era [J] Exploration and Free Views, 2020, 371 (09).

[2] Yang Biao. Information Governance and Social Discrimination: The strategy and practice legislation in China [J] Sociological Study, 2015, 30 (06).

[3] Stewart Schwab. Is Statistical Discrimination Efficient? [J] The American Economic Review, 1986, 76 (01).

[4] James Gordley. Foundation of Privacy Law: property, tort, contract, unjust enrichment [M] Beijing: Law Press, 2007.

[5] Thompson M. The Biographical Core of Law: Privacy, Personhood, and the Bounds of Obligation [J] Social Science Electronic Publishing, 2018.

[6] Victor Myer-Schoenberg (author). Yuan Jie (translation). Delete: the virtue of forgetting in digital age $[\mathrm{M}]$ Hanzhou: Zhejiang University Press, 2013.
[7] Wang Liming. Research on Personality Right Law (Third Edition) [M] Beijing: China Renmin University Press, 2018.

[8] Yumeng Bao. Baidu Robin Li: in most cases, Chinese people are willing to use privacy to exchange convenience, 2021, 08, 27.

[9] Li Jibo, Ma Shaojian. From today on, passengers taking the Changsha subway needs to be checked for the vaccination of Covid-19, 2021, 08, 29.

[10] Lum, K. and Isaac, W.To predict and serve? https://doi.org/10.1111/j.1740-9713, 2016.00960.x, 2021, 08, 27.

[11] Sonia K. Katyal. Private Accountability in the Age of Artificial Intelligence [J] Exploration and Free Views, 2020, 371 (62-77).

[12] Wen Yu. Reflection on the relationship between rights and obligations in search engine data trace processing -- taking two Baidu litigation cases as the starting point [J] Oriental law, 2020 (06).

[13] Beijing First Intermediate People's Court. Judgment of the second instance of the first case of China's right to be forgotten - Ren Jiayu v. Baidu case, 2021, $08,27$.

[14] Peyton, Claire (author). Zheng Shuhong (translation). Privacy in the age of big data [M] Shanghai: Shanghai Science and Technology Press, 2016.

[15] James Ball. CostejaGonzálezanda memorable fight for the right to be forgotten, 2021, 08, 27. https://www.theguardian.com/world/blog/2014/ma y/14/mario-costeja-gonzalez-fight-right-forgotten.

[16] Zhao Qiang. Dig data-enabled price discrimination against existing customers is to be punished to pain, 2021, 8, 27.

https://baijiahao.baidu.com/s?id=17015599792559 $46248 \& w f r=$ spider $\&$ for $=$ pc.

[17] A A cquisti, Brandimarte L, Loewenstein G. Privacy and human behavior in the age of information $[\mathrm{J}]$ Science, 2015, 347 (6221).

[18] Ong R, Sabapathy S. Enhancing patient privacy protection under Hong Kong's Electronic Health Record Sharing System [J] Common Law World Review, 2020, 49 (1).

[19] Supreme People's Procuratorate. Personal information protection into the legal field of procuratorial public interest, 2021, 08, 27. https://mp.weixin.qq.com/s/TL3YURsuAnP6_pL8J FlK.

[20] Thompson M. Beyond Gatekeeping: The Normative Responsibility of Internet Intermediaries [J] Vanderbilt Journal of Entertainment \& Technology Law, 2026, 18 (04). 